\title{
Dynamical response of a multi-laminated periodic bar: Analytical, numerical and experimental study
}

\author{
H. Policarpo ${ }^{\text {a }}$, M.M. Neves ${ }^{b, *}$ and A.M.R. Ribeiro ${ }^{b}$ \\ ${ }^{a}$ DEM, Instituto Superior Técnico, Tech. Univ. of Lisbon, Av. Rovisco Pais, 1049-001 Lisboa, Portugal \\ ${ }^{\mathrm{b}}$ IDMEC-IST, Instituto Superior Técnico, Tech. Univ. of Lisbon, Av. Rovisco Pais, 1049-001 Lisboa, Portugal
}

\begin{abstract}
This article presents a study on the use of the dynamical response of multi-laminated periodic bars to create resonance band gaps within useful frequency ranges. The objective is to control, in a passive form, the longitudinal vibration transmissibility in specific and wide enough frequency ranges of interest. This is achieved by the separation of two adjacent eigenfrequencies. A relation between the modal analysis, the harmonic analysis and the Bloch wave theory is proposed, for which no reference was found in the searched literature. As shown, the selection of appropriate material pairs is essential to obtain useful frequency ranges. The use of pairs of steel and cork agglomerate is proposed, since it allows the design of attenuators at lower frequencies through a prediction based on finite element analysis (FEA). This approach requires the storage modulus of cork for which analytical and numerical FEA models were verified and validated. A methodology to obtain experimentally the storage modulus of cork is presented. Regarding the structural improvement problem, we discuss a methodology to design periodic bars for a specific location of the first attenuation's frequency range and illustrate the main results through several examples.
\end{abstract}

Keywords: Passive isolation, vibration, multi-laminated bar, cork agglomerates, structural modification

\section{Introduction}

Active systems are commonly used in vibration isolation applications although they are expensive and in some cases have low reliability. Passive vibration devices have considerable limitations that continue to receive attention from researchers and continue to be improved as can be seen, for e.g., in [1]. In this context, several authors [2] have demonstrated that in most cases the requirements for vibration isolation of a set of specific high precision tools can be satisfied with a proper selection of passive isolators. Development of vibration isolators for low frequencies is still a challenge. This can be seen in the works of [3] and [4] where dynamic vibration absorbers and lever type anti-resonant vibration isolators are formulated and used to design lightweight and stiff uniaxial passive vibration isolators with wide stop bands.

Multi-laminated structures have received considerable attention and extensive efforts have been made to analyze the propagation of waves in periodic structures. Among these efforts is the unified approach of Brillouin for the dynamic analysis of a wide variety of periodic structures [5]. Apart from their unique filtering characteristics, the ability of periodic structures to transmit waves from one location to another, within the pass-bands, can be greatly reduced when the ideal periodicity is disrupted or disordered [6]. Another relevant characteristic of periodic structures is to stop wave transmission from one location to another within the stop-bands which can also be greatly improved when the ideal periodicity is disrupted.

${ }^{*}$ Corresponding author. Tel.: +351 218417547; Fax: +351 218474045; E-mail: maneves@dem.ist.utl.pt. 
Among the pioneering efforts is also the work of Mead and his co-workers [7] which includes many of the original contributions to the analysis and characterization of the wave propagation in periodic structures. To study structures built with infinite periodicity repetition, Bloch's theorem [8], also related with Lyapunov-Floquet's theorem [9], can be used to obtain a characterization of longitudinal waves leading to the corresponding dispersion relation. For structures with finite periodic repetition, a description of the basics can be found in [10-15].

In this study, multi-laminated periodic bars are used to separate two adjacent eigenfrequencies creating wide resonance gaps at useful frequencies. For this purpose, three different but complementary approaches are considered: the analytical, the numerical and the experimental. The main objective is to control, in a passive form, longitudinal vibration transmissibility in a specific and wide enough frequency range of interest, designated as resonance gap, also referred to as attenuation region.

The present study is motivated by the lack of work found dealing with frequency ranges of practical interest for these types of structures even though they have been widely researched over the years. The layout of the materials and the contrasting ratio of their properties (specifically, the wave propagation speed) determine the widths and locations of the resonances gaps [15]. Thus, for low frequency ranges a high contrasting ratio of the properties of the materials is required. We propose the use of steel and cork or cork agglomerate pairs because they present such high contrasting ratio of properties [16]. However there is a considerable lack of research publications on cork agglomerates in this area.

The multi-laminated periodic bar is used since it allows for obtaining a significantly wider resonance gap between some selected adjacent eigenfrequencies relative to the homogeneous bar or to helicoidal springs that generally present uniformly spaced resonances. The reason for using a steel-cork agglomerate, multi-laminated periodic bar is its potential usefulness for low frequency ranges as well as its predictable response by FEA.

To simplify the problem, it is assumed that each material is isotropic and exhibits linear-elastic behavior. The structural models are limited to the elastic bar model (i.e., link or rod elements). No damping effects are considered. The multi-laminated bar is modeled using finite elements and verified relatively to existing work [17]. After verifying the numerical models $[18,19]$, an experimental analysis is performed to reproduce the numerical results obtained and consequently validate the developed models.

Steel and cork agglomerate are used in the construction of the experimental specimens. As evidenced in creep experiments [20] and from Dynamic Mechanical Analysis (DMA) the visco-elastic character of cork is presented here. Indeed, the static modulus differs from the storage modulus, and therefore the static modulus cannot be used for this purpose as it is done with steel (at ambient temperature and pressure). Through the experimental validation process, a methodology to determine the storage modulus of cork [21] was used with similar results to those obtained by DMA [22].

The design methodology presented has potential use in the development of vibration isolation structures, sound isolation pads/partitions, and multiple band frequency filters, among other applications. The methodology proposed reveals a new perspective on the problem from where a relation between the eigenfrequency results (modal problem), the frequency response (harmonic problem) and the dispersion relations (Bloch wave problem) is observed and for which no reference was found in the researched literature. To illustrate the new perspective a simple structural improvement problem is introduced which reveals significant attenuations for the case of longitudinal vibrations.

\section{Analytical model}

Consider the structure, as illustrated in Fig. 1, with parallel alternating layers (half-cells) of two-material differing in wave speed $c=\sqrt{E / \rho}$ where $E$ is the longitudinal modulus of elasticity (Young's modulus) and $\rho$ is the mass density.

The axial vibrations are governed by the differential equation:

$$
E_{\alpha} A \frac{\partial^{2} u_{\alpha}(x, t)}{\partial x^{2}}-\rho_{\alpha} A \frac{\partial^{2} u_{\alpha}(x, t)}{\partial t^{2}}=F(x, t), \alpha=1,2
$$

where $\alpha$ is layer's type, $A$ is the cross-sectional area, $E_{\alpha}$ is the longitudinal modulus of elasticity, $\rho_{\alpha}$ is the mass density, $u_{\alpha}(x, t)$ is the displacement at the longitudinal coordinate $x$ and at time $t$ and $F$ is a distributed force. The 


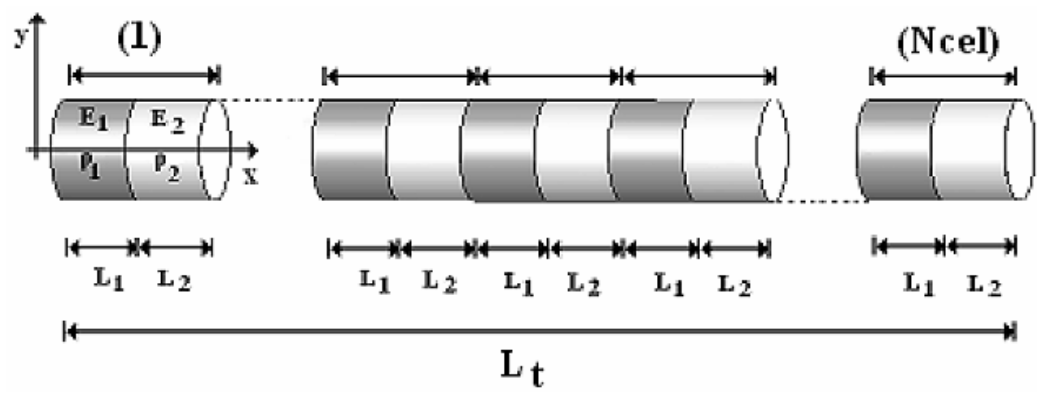

Fig. 1. Periodic bar made of two different materials.

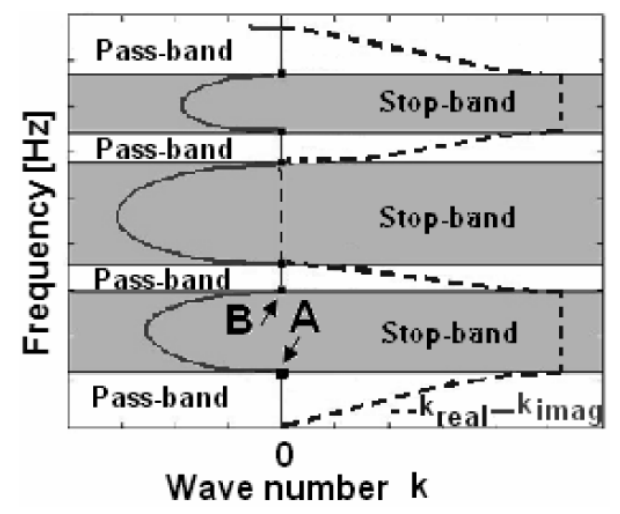

Fig. 2. Dispersion curves obtained from Eq. (3).

displacements $u_{\alpha}(x, t)$ and stresses $\sigma_{\alpha}(x, t)$ will be considered continuous at the layer boundaries. Essentially, the analyses in this study are restricted to linear elastic material.

By virtue of the structure's periodicity, eigenmodes can be characterized by a quasi-wave number $k=\omega / c$ assuming that the displacement field in a repetitive cell takes the form

$$
u_{i}(x)=u_{0}(x-i L) e^{j(k i L)}, i=1,2, j=\sqrt{-1},
$$

where $i$ is the cell's number, $L$ is the structure's period and $u_{0}$ is the periodic solution, i.e. $k=0$. For this case, the dispersion equation [23] is a function of the quasi-wave number

$$
k=\frac{1}{L} \cos ^{-1}\left[\cos \left(k_{1} L_{1}\right) \cos \left(k_{2} L_{2}\right)-\frac{1}{2}\left(\frac{k_{1}}{k_{2}}+\frac{k_{2}}{k_{1}}\right) \sin \left(k_{1} L_{1}\right) \sin \left(k_{2} L_{2}\right)\right],
$$

where the wave numbers are $k_{1}=\omega / c_{1}$ and $k_{2}=\omega / c_{2}, \omega$ is the excitation frequency and $c_{1}$ and $c_{2}$ are the wave's propagation speeds in the type 1 and 2 layers, respectively. $L_{1}$ and $L_{2}$ represent the layer's thicknesses (in axial direction). Then, the structure's period is given by $L=L_{1}+L_{2}$ (see Fig. 1). Equation (3) allows computing and plotting the frequency as an implicit function of the quasi-wave number for this type of structure. For values of frequency that make the wave number complex, the amplitude of the displacement is attenuated exponentially. Under such conditions, the frequency bands where $k$ is complex are called stop-bands while the bands within intervals where $k$ is real are called pass-bands. A common representation for these cases is the plot of dispersion curves, illustrated by Fig. 2 .

\section{Numerical model}

In this study, the formulation of the finite element is based on the following main assumptions: the material presents a linear elastic behavior and is isotropic and homogeneous; the displacements and/or deflections are small 
in comparison to the characteristic dimensions of the element; the element is of length $L$ and has two nodes, one at each end; the element is connected to other elements only at the nodes; element loading occurs only at the nodes; the bar element considers only axial loading thereby ignoring bending, torsion, and shear that are not transmitted to the element via the nature of its connections to other elements.

In this study, no damping effects are considered and two different analysis are presented [24]: Modal Analysis:

$$
\left([K]-\omega^{2}[M]\right)\{\Phi\}=\{0\},
$$

Harmonic Analysis:

$$
\left([K]-\omega_{a p}^{2}[M]\right)\{u\}=\left\{F_{\omega_{a p}}\right\} .
$$

The modal analysis consists of calculating the natural vibration mode shapes $\{\Phi\}$ and eigenfrequencies $\omega$ of the system by solving the free undamped problem, Eq. (4), reveals the possible existence of harmonic body motion when no forces are applied. The harmonic response analysis expressed by Eq. (5) is used to find the steady-state response of the linear structure subjected to axial load $F_{\omega_{a p}}$ with excitation frequency $\omega_{a p}$.

The multi-laminated bar is modeled by a 1D elastic finite element bar with uniaxial tension or compression that reduces the analysis to one degree of freedom at each of the two nodes: translations in the nodal $x$ direction. The finite element stiffness $\left[K_{e}\right]$ and mass $\left[M_{e}\right]$ matrixes and force $\left\{F_{e}\right\}$ vector with length $L$ are

$$
\left[K_{e}\right]=\frac{E(x) A}{L}\left[\begin{array}{cc}
1 & -1 \\
-1 & 1
\end{array}\right],\left[M_{e}\right]=\frac{\rho(x) A L}{6}\left[\begin{array}{ll}
2 & 1 \\
1 & 2
\end{array}\right],\left\{F_{e}\right\}=\left\{\begin{array}{l}
F_{1} \\
F_{2}
\end{array}\right\},
$$

where $A$ is the cross-sectional area, $E(x)$ and $\rho(x)$ are the longitudinal modulus of elasticity and mass density of each material layer, respectively, and $F_{1}$ and $F_{2}$ are the nodal forces.

The structural analyses of Eqs (4-5) [25] are computed with no transversal displacements, i.e. $\mathrm{U}_{y}=0$ for all nodes and $\mathrm{U}_{x}=0$ at $\mathrm{x}=\mathrm{L}_{t}$ (see Fig. 1).

\section{Selection of materials}

The material selection is essential to this study since we are targeting low frequency ranges of practical interest. Four different materials, namely aluminum, epoxy and cork agglomerate, are individually combined with steel.

As previously discussed, the widths and locations of the resonance gaps are determined by the material layout and the contrasting ratio of the material properties used. Among the materials studied, steel and cork agglomerate present the highest contrasting ratio in wave propagation speed. Thus, this combination is the recommended pair to target the intended low frequency ranges in this study. For the dynamical analysis with cork or cork agglomerate, it is necessary to have its storage modulus that is not usually available and may present considerable variability [20].

\section{Experimental model}

In the initial stage of the experimental study, routine hardware and software calibration tests and primary specimen analysis were performed (e.g., to study the influence of the adhesive's layer) which were useful in the improvement of the finite element model. Several specimens were built and tested. An epoxy based structural adhesive was used in the construction of the specimens to bond the different material half-cells along the specimen lengths. Even though the adhesive introduces a relatively thin layer of material, a brief analysis was performed to determine how it affects the experimental results, and as described in [26], we conclude that there was no significant influence.

The experimental setup is illustrated in Fig. 3. The input signals are generated and transmitted to a shaker; the force effectively applied to the specimen was measured through a force transducer. The dynamical deformation propagates through the specimen and, at the opposite extremity, an accelerometer measures the longitudinal acceleration (output signal). 


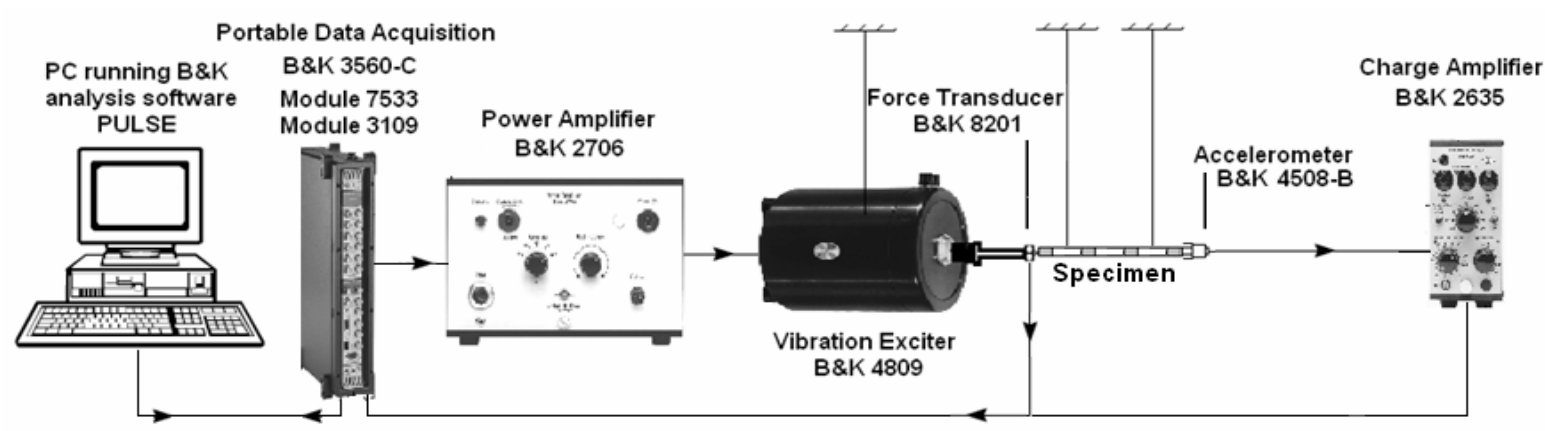

Fig. 3. Scheme illustrating the experimental setup.

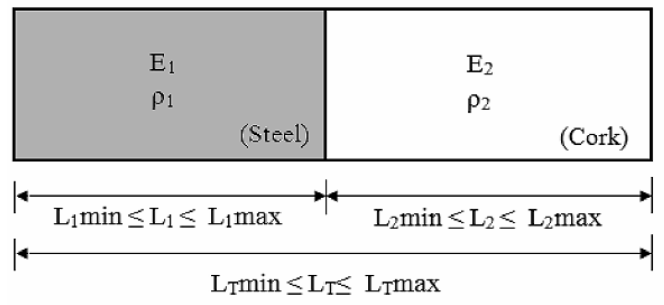

(a)

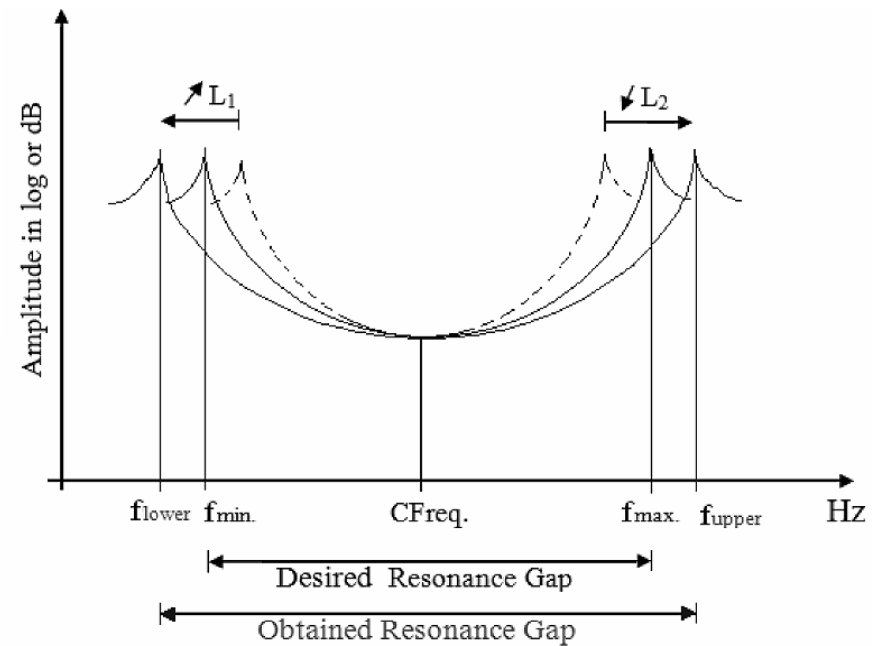

(b)

Fig. 4. a) Unit cell; and b) Frequency response curves illustrating $f_{\min .}, f_{\text {max. }}, f_{\text {lower }}, f_{u p p e r}$, CFreq and RG.

\section{Structural improvement and structural optimization}

To target a desired resonance gap frequency range, the design of a unit cell as illustrated in Fig. 4 a) may be considered as one of the most important steps in the design stage of the multi-laminated periodic rod. Structural improvement and structural optimization are used for this purpose.

\subsection{Structural improvement}

Consider a unit cell illustrated in Fig. 4 a) made of two materials with high contrast in their elastic properties (E and $\rho$ ), e.g. steel and cork agglomerate. The length of each material layer, i.e. $\mathrm{L}_{1}$ and $\mathrm{L}_{2}$, is the design parameter. The improvement problem is subject to several length constraints, namely, minimum and maximum material layer's length as well as a minimum and maximum total length of the cell.

As previously introduced in Section 2, the dispersion equation allows computing and plotting the frequency as an implicit function of the quasi-wave number $k$ obtaining the dispersion curves where the stop band and pass band regions may be identified (see Fig. 2). Solving the dispersion equation would be an alternative to the numerical finite element model for the design of a unit cell if it were differentiable in a specific domain. Figure 2 illustrates the dispersion curves where points A and B represent the initial and final points, respectively, of the first stop band. In 
these points, the dispersion equation is not differentiable. The numerical identification of non-differentiable points is not easy and is not considered in this study.

Alternatively, the numerical finite element model introduced in Section 3 is used. The modal and/or harmonic problems are solved with a total of 5.5 unit cells, although more than three unit cells are considered to be enough for the dynamic behavior of a finite periodic structure to qualitatively match that of the infinite periodic structure [12]. In addition, 16 finite elements per wavelength are used which is considered enough in this study [26].

The desired resonance gap (RG) may be defined by the minimum $\left(f_{\text {min. }}\right)$ and maximum $\left(f_{\text {max. }}\right)$ resonance gap frequencies, that are equivalent to points A and B, respectively, illustrated in Fig. 2, or by a center frequency (CFreq.) and bandwidth (BW).

A main concept introduced in [26] is that 1$)$ the maximum frequency of the RG ( $\left.f_{\text {max. }}\right)$ increases when the length of material layer $2\left(\mathrm{~L}_{2}\right)$ is decreased and 2$)$ increasing the length of material layer $1\left(\mathrm{~L}_{1}\right)$ the minimum frequency of the RG $\left(f_{\min }\right.$. ) decreases. A design procedure for these types of cells is developed here based on this concept and applied as illustrated in Fig. 5.

The design procedure starts with the option of the desired inputs parameters, i.e., the minimum and maximum resonance gap frequencies or the center frequency and bandwidth. This is followed by defining the previously chosen parameters as well as the elastic properties $(\mathrm{E}$ and $\rho)$ and the length $\left(\mathrm{L}_{1}\right.$ and $\left.\mathrm{L}_{2}\right)$ of the material layers. Then, the maximum and minimum geometrical parameters of each material are defined.

The modal analyses of Section 5 is in our case solved by the commercial finite element environment ANSYS ${ }^{\circledR}$. The lower $\left(f_{\text {lower }}\right)$ and upper $\left(f_{\text {upper }}\right)$ resonance gap frequencies are computed, which correspond to the fifth and sixth eigenfrequencies for the case of 5.5 unit cells.

The upper $\left(f_{\text {upper }}\right)$ and maximum $\left(f_{\text {max. }}\right.$ ) resonance gap frequencies are compared. While $f_{\text {max. }}>f_{\text {upper }}$ the length of material $2\left(\mathrm{~L}_{2}\right)$ is decreased by $10 \%$ until $\mathrm{L}_{2}<\mathrm{L}_{2} \mathrm{~min}$. Once this constraint is satisfied the lower ( $\mathrm{f}_{\text {lower }}$ ) and minimum $\left(f_{\text {min }}\right.$.) resonance gap frequencies are then compared. While $f_{\text {min. }}<f_{\text {lower }}$ the length of material layer $1\left(\mathrm{~L}_{1}\right)$ is increased by $10 \%$ until $\mathrm{L}_{1} \leqslant \mathrm{~L}_{1}$ max. The order in which the material lengths change is important, since an increase in the length of material $1\left(\mathrm{~L}_{1}\right)$ will not significantly affect the value of the upper $\left(\mathrm{f}_{\text {upper }}\right)$ resonance gap frequency previously obtained, as it will be shown. If no constraint is violated when stopped, a feasible solution is found. The value of $10 \%$ is used to increase/decrease lengths as it presents a good compromise between computational speed and results convergence.

Alternatively, an optimization method may solve this problem. However, an objective function that considers both design regions $\left(\left[f_{\text {min. }} ; f_{\text {lower }}\right]\right.$ and $\left.\left[f_{\text {max. }} ; f_{\text {upper }}\right]\right)$ may have some problems regarding the upper region (from a practical application point of view) which are discussed here.

\subsection{Structural optimization}

A structural optimization procedure that avoids including the upper and/or the lower design regions in the objective function can be obtained by defining a mass ratio cost function. The optimization problem is formulated as,

$$
\begin{aligned}
& \min _{L_{1}, L_{2}}\left(\frac{\rho_{1} L_{1}}{\rho_{2} L_{2}}\right) \\
& \text { s.t. } \\
& \left([K]-\omega^{2}[M]\right)\{\Phi\}=\{0\}, \\
& f_{\text {Lmin. }} \leqslant f_{\text {lower }} \leqslant f_{\text {Lmax. }} . \\
& f_{\text {Umin. }} \leqslant f_{\text {upper }} \leqslant f_{\text {Umax. }} . \\
& \mathrm{L}_{1} \text { min } \leqslant \mathrm{L}_{1} \leqslant \mathrm{~L}_{1} \text { max. } \\
& \mathrm{L}_{2} \text { min } \leqslant \mathrm{L}_{2} \leqslant \mathrm{~L}_{2} \text { max. }
\end{aligned}
$$

where $\rho_{1}$ is the mass density of material $1, \rho_{2}$ is the mass density of material $2, f_{\text {Lmin }}$ is the minimum lower frequency allowed, $f_{\text {Lmax. }}$ is the maximum lower frequency allowed, $f_{\text {Umin. }}$ is the minimum upper frequency allowed and $f_{\text {Umax. }}$ is the maximum upper frequency allowed. 


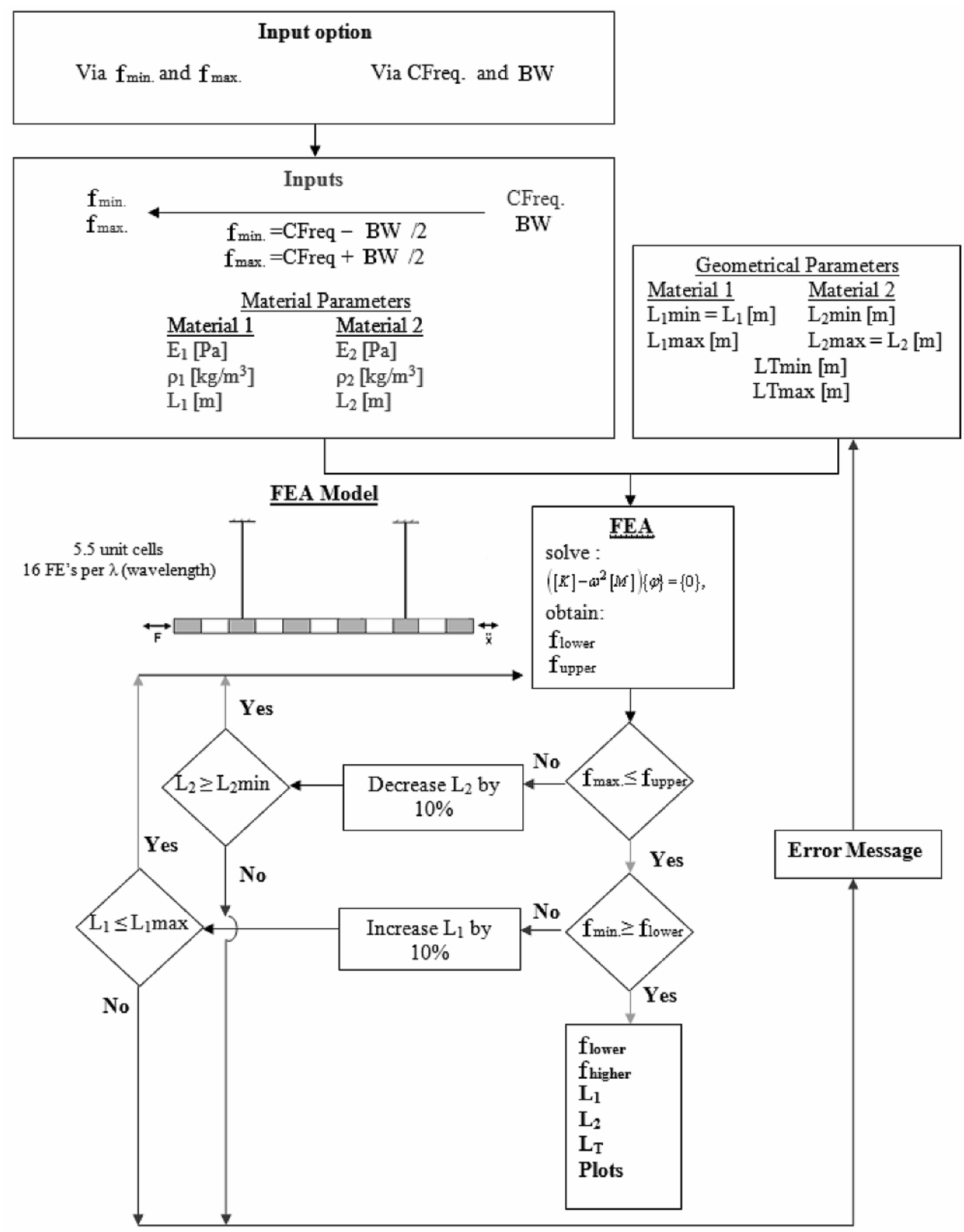

Fig. 5. Diagram of the design procedure/method applied to the design of a unit cell.

\section{Results and discussion}

The results obtained are presented and discussed in this section. We show that the steel and cork agglomerate is the material pair that fits the intended frequency range of interest in this study. Two experimental steel-cork agglomerate specimens were built and experimental results are compared with those obtained numerically. This is followed by the presentation of some examples of structural improvement and optimization. 


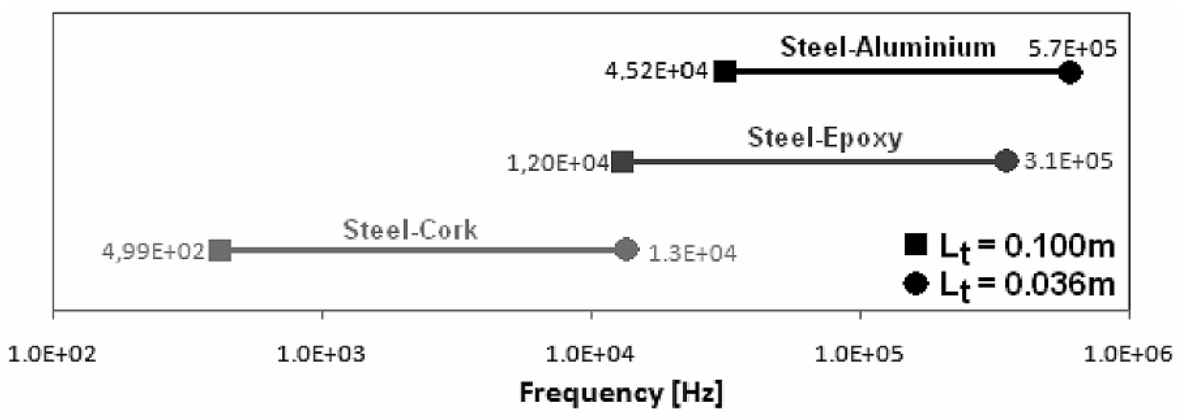

Fig. 6. First wide resonance gap (i.e. position of point A indicated at Fig. 2) for some pairs of materials.

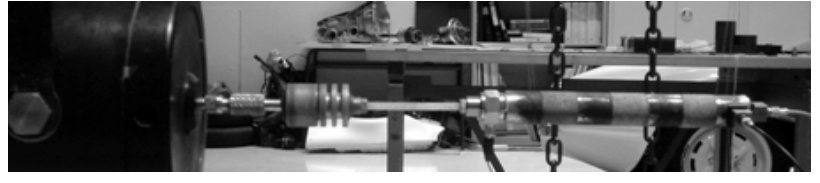

a)

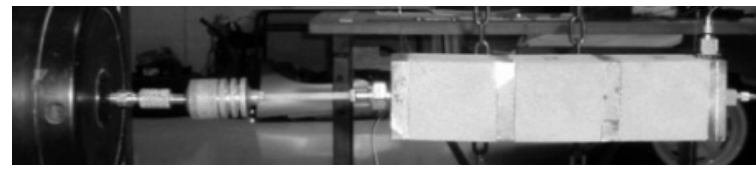

b)

Fig. 7. Experimental setup for a 3.5 cells heterogeneous bar: a) steel-commercial cork agglomerate specimen; b) steel-cork agglomerate (ref. 8123 [27]) specimen.

\subsection{Comparison of some results from material selection}

As referred in Section 4, the material selection is essential in this study, since we are targeting frequency ranges of practical interest. For it, four different materials were studied. Aluminum with $E=70 \mathrm{GPa}$ and $\rho=2700 \mathrm{~kg} / \mathrm{m}^{3}$; epoxy with $E=4.5 \mathrm{GPa}$ and $\rho=1100 \mathrm{~kg} / \mathrm{m}^{3}$ and cork agglomerate with $E=43 \mathrm{MPa}$ and $\rho=260 \mathrm{~kg} / \mathrm{m}^{3}$ were individually combined with steel with $E=200 \mathrm{GPa}$ and $\rho=7860 \mathrm{~kg} / \mathrm{m}^{3}$.

Parametric finite element analysis were performed using modal analysis given by Eq. (4) to obtain the frequency range locations targeted by each specimen, as illustrated by Fig. 6 . For the specimen a total length $\mathrm{L}_{t}$ between 0.036 $\mathrm{m}$ and $0.100 \mathrm{~m}$ and a total number of cells Ncel $=6$ (see Fig. 1) were considered. The left points (lower bounds) of each horizontal line in Fig. 6 are calculated for $\mathrm{L}_{t}=0.1 \mathrm{~m}$ and the right points (upper bounds) of each horizontal line are calculated for $\mathrm{L}_{t}=0.036 \mathrm{~m}$.

The steel and cork agglomerate seems to fit the intended frequency range of interest in this study.

\subsection{Comparison between experimental and numerical results}

Two experimental specimens with 3.5 unit cells were built and tested. Fig. 7 a) illustrates the experimental setup for a cylindrical bar specimen with a uniform diameter of $0.020 \mathrm{~m}$ composed of four steel and three standard commercial cork agglomerate layers each with a length of $0.020 \mathrm{~m}$. Fig. $7 \mathrm{~b}$ ) illustrates the experimental setup for a bar with a square cross-section with a side length of $0.050 \mathrm{~m}$ composed of four steel and three cork agglomerate (ref. 8123, see e.g. [27]) half-cells each with a length of $0.010 \mathrm{~m}$ and $0.050 \mathrm{~m}$, respectively. The half-cells were bonded with an epoxy structural adhesive.

Figures 8 a) and b) illustrate the frequency response curves obtained numerically (dashed curves) and experimentally (fill curves) for each of the two specimens (see Fig. 7). The first resonance is indicated by the first vertical filled black line and the first wide resonance gap is indicated by the shaded area. The storage modulus E' of each cork agglomerate is extracted from the first natural frequency of each specimen [21]. Figs 8 a) and b) illustrate the first natural frequencies of each specimen that correspond to $352 \mathrm{~Hz}$ and $368 \mathrm{~Hz}$, respectively. Based on these values, the storage modulus E' of each cork agglomerate was found to be approximately $27 \mathrm{MPa}$ and $43 \mathrm{MPa}$, respectively. These values are consistent with published work [20] and are validated by the correlation obtained between the experimental and numerical results as it is illustrated in Figs 8 a) and b). 


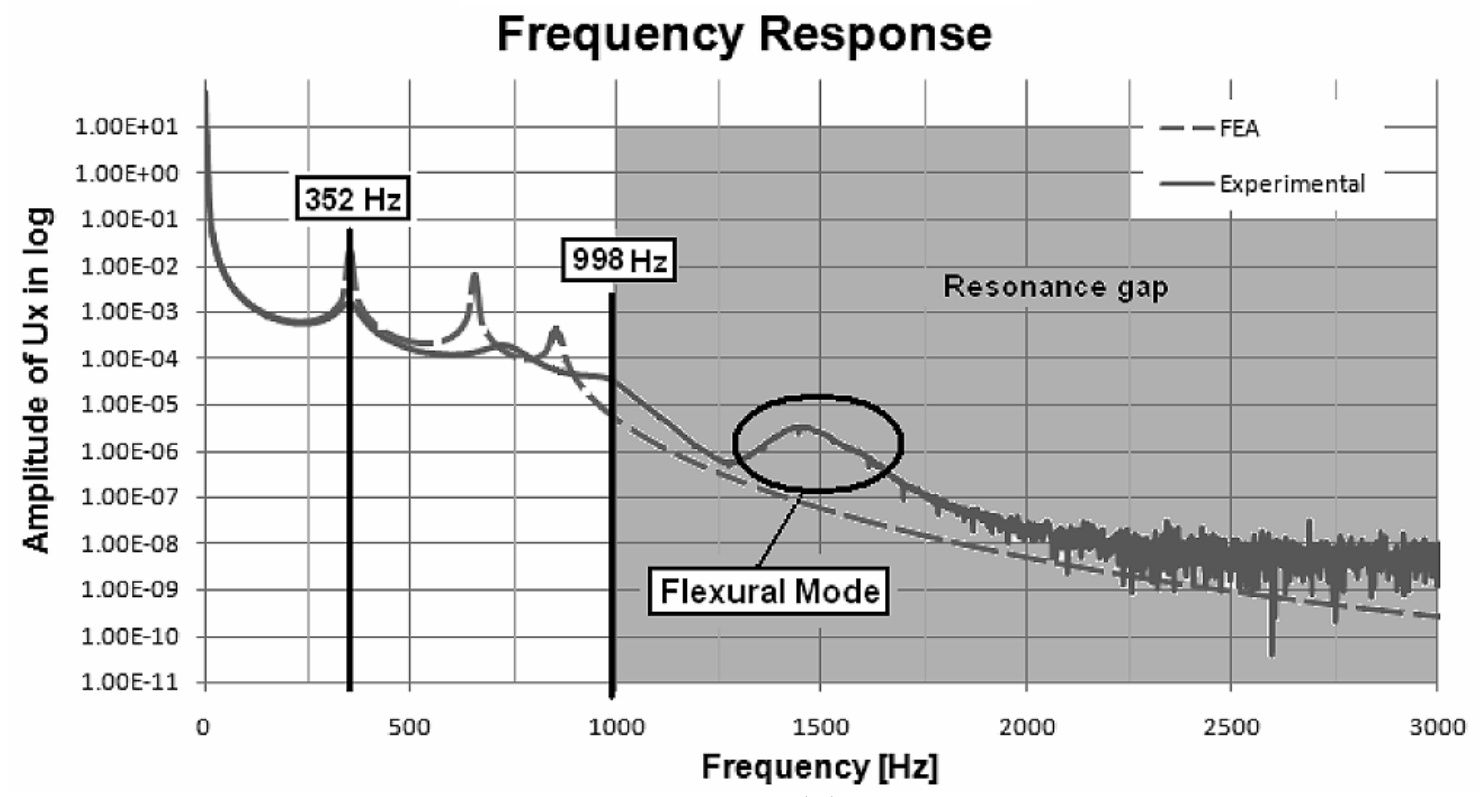

(a)

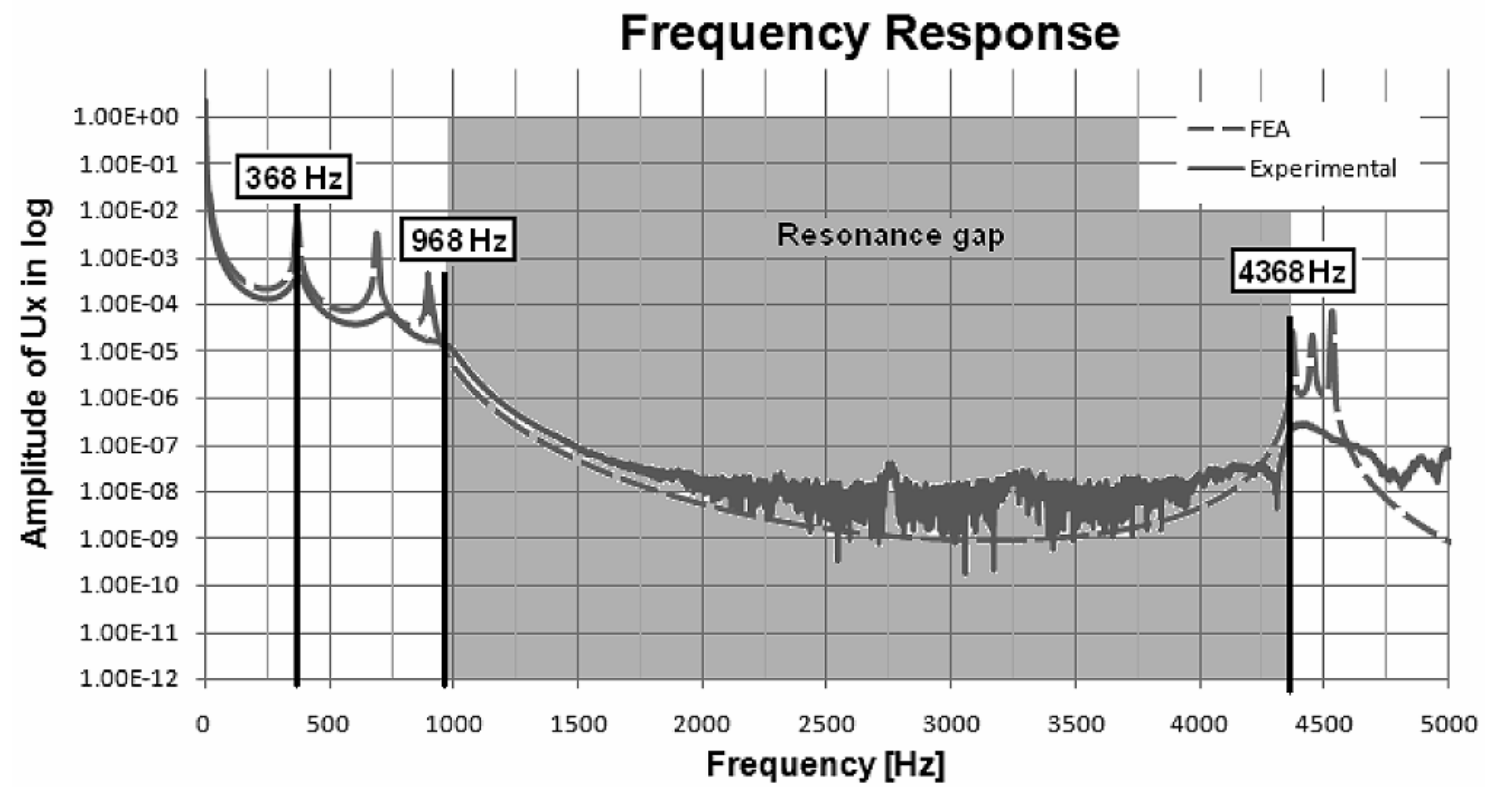

(b)

Fig. 8. Frequency response curves: a) steel-commercial cork agglomerate specimen; b) steel-cork agglomerate (ref. 8123 [27]) specimen.

In Fig. 8 a) a flexural vibration mode is identified in the experimental analysis curve which was considered out of the scope of this study.

The filtering characteristics of these types of structures were experimentally verified as can be seen from the satisfactory correlation in the localization of resonance gaps as indicated by the shaded areas in Figs 8 a) and b).

Relative to the displacement amplitude, some discrepancy is noted at higher frequencies which we consider mainly due to the following facts: the numerical model does not include damping; and the accelerometers sensitivity at higher frequencies is affected by the use of mounting clips. This will be subject of future work. 
Table 1

Output results from the structural improvement case

\begin{tabular}{lcc}
\hline & $\mathbf{L}_{2}(\mathbf{m})$ & $\Delta \mathbf{f}=\left(\mathbf{f}_{i+1}-\mathbf{f}_{i}\right)(\mathbf{H z})$ \\
\hline Initial & $6.00 \times 10^{-3}$ & 3440 \\
Improved & $1.20 \times 10^{-3}$ & 20160 \\
\hline
\end{tabular}

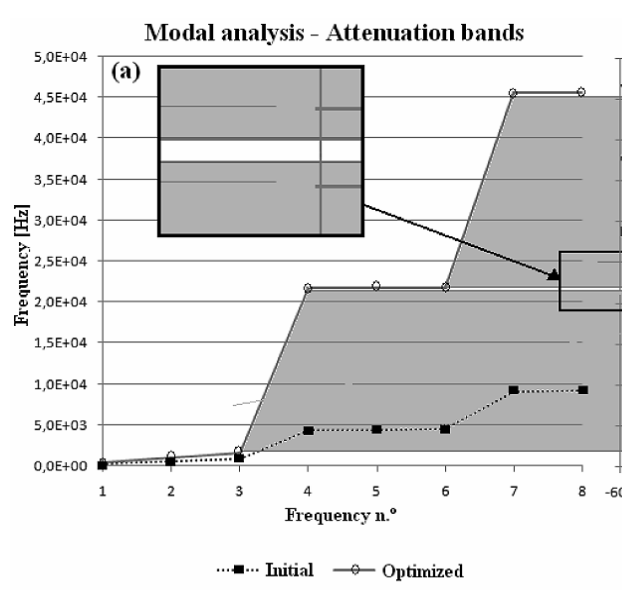

(a)

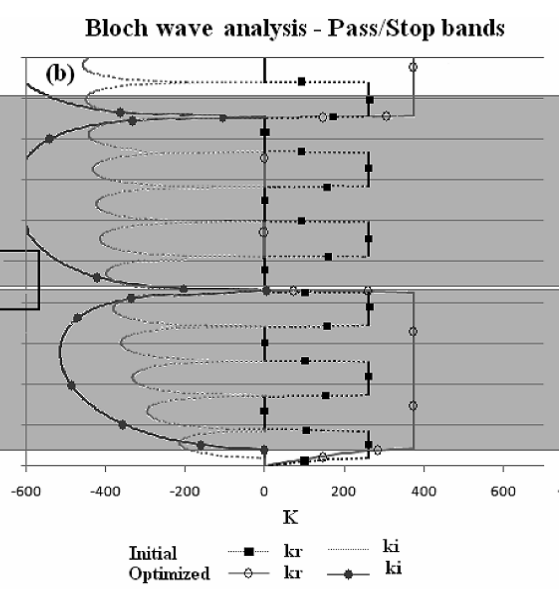

(b)

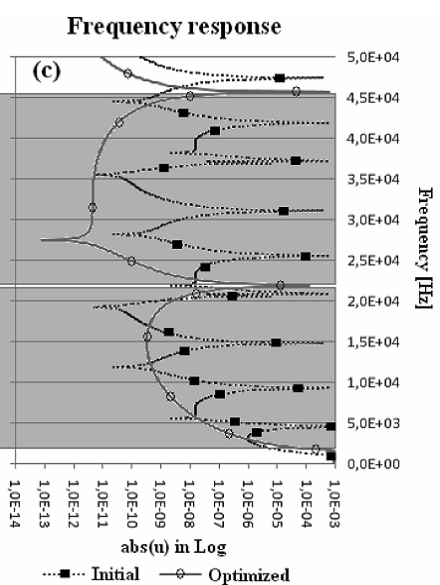

(c)

Fig. 9. Results for $i=N c e l=3$ cells: a) Eigenfrequencies curve plot; b) Dispersion curves and c) Frequency response plot.

Relative to the values of the resonant frequencies, some discrepancy is noted for the second and third resonances which we consider mainly due to the following facts: in the numerical model the storage modulus of elasticity of cork was considered constant but, due to the viscoelastic character of cork [20], it may be frequency dependant; for frequency dependant material properties, the techniques for viscoelastic material characterization [22] may be adopted but were not considered necessary to demonstrate the method presented in this work; also, the finite element model updating [28] on the mass, stiffness and damping matrices and/or the use of correlation functions [29] of the frequency response function, e.g., Frequency Response Assurance Criterion (FRAC) values [30] could improve the FE model match to the experimental curves. These issues will be subjects of future work.

\subsection{Structural improvement results - Example 1}

The first structural improvement problem consists of increasing the axial length $\mathrm{L}_{2}$ of each unit cell while maintaining the total length $\mathrm{L}_{1}+\mathrm{L}_{2}$ of the repetitive cell (see Fig. 1).

It was assumed that the bar has a uniform diameter of $0.01 \mathrm{~m}$, a total length of $\mathrm{L}_{t}=0.036 \mathrm{~m}$ and the two material properties are: $\mathrm{E}_{1}=205.0 \mathrm{GPa}, \rho_{1}=7860 \mathrm{~kg} / \mathrm{m}^{3}$ and $\mathrm{E}_{2}=0.003 \mathrm{GPa}, \rho_{2}=1140 \mathrm{~kg} / \mathrm{m}^{3}$. The initial design consisted of $\mathrm{L}_{1}=\mathrm{L}_{2}=\mathrm{L}_{t} /(2 * \mathrm{Ncel})$ with $\mathrm{Ncel}=3$.

Improvement in the separation of two adjacent frequencies ( $\mathrm{i}$ and $\mathrm{i}+1$ ) relative to the initial design, i.e. from initial separation $\Delta \mathrm{f}_{i n i}$ to improved final value $\Delta \mathrm{f}_{f i n}$, were obtained as shown by the values in Fig. 9 a), for $i=$ 3. The dispersion curves obtained as described in Section 2 are presented in Fig. 9 b). The frequency response of displacement at node $\mathrm{x}=\left(\mathrm{L}_{t}-\left(\mathrm{L}_{t} / \mathrm{Ncel}\right)\right)$ is presented at Fig. $\left.9 \mathrm{c}\right)$ for an applied axial harmonic force with $200 \mathrm{~N}$ of magnitude at $x=0 \mathrm{~m}$. The resonance gaps are identified (by the gray areas) and related with the stop-bands given by the dispersion curves. The Bloch wave analysis previously introduced in Section 2 consists of solving the characteristic equation Eq. (3), whose roots give the corresponding wave number $k$ for each given frequency $\omega$.

The separations of the adjacent eigenvalues, expressed by $\Delta \mathrm{f}$, are evident (see Table 1) when comparing the initial design curves with corresponding curves of the improved design. 
Table 2

Target and design values for example 2

\begin{tabular}{lcc}
\hline & Target & Design (obtained) \\
\hline $\mathbf{f}(\mathbf{H z})$ & $\mathrm{f}_{\text {min. }}<1000$ & $\mathrm{f}_{\text {lower }}=980$ \\
$\mathbf{f}(\mathbf{H z})$ & $\mathrm{f}_{\max .}>4100$ & $\mathrm{f}_{\text {upper }}=4139$ \\
$\mathbf{L}_{1}(\mathbf{m})$ & $0.01 \leqslant \mathrm{~L}_{1} \leqslant 0.05$ & 0.01 \\
$\mathbf{L}_{2}(\mathbf{m})$ & $0.01 \leqslant \mathrm{~L}_{2} \leqslant 0.05$ & 0.05 \\
$\mathbf{L}_{T}(\mathbf{m})$ & $0.02 \leqslant \mathrm{~L}_{T} \leqslant 0.10$ & 0.06 \\
\hline
\end{tabular}

Resonance gap

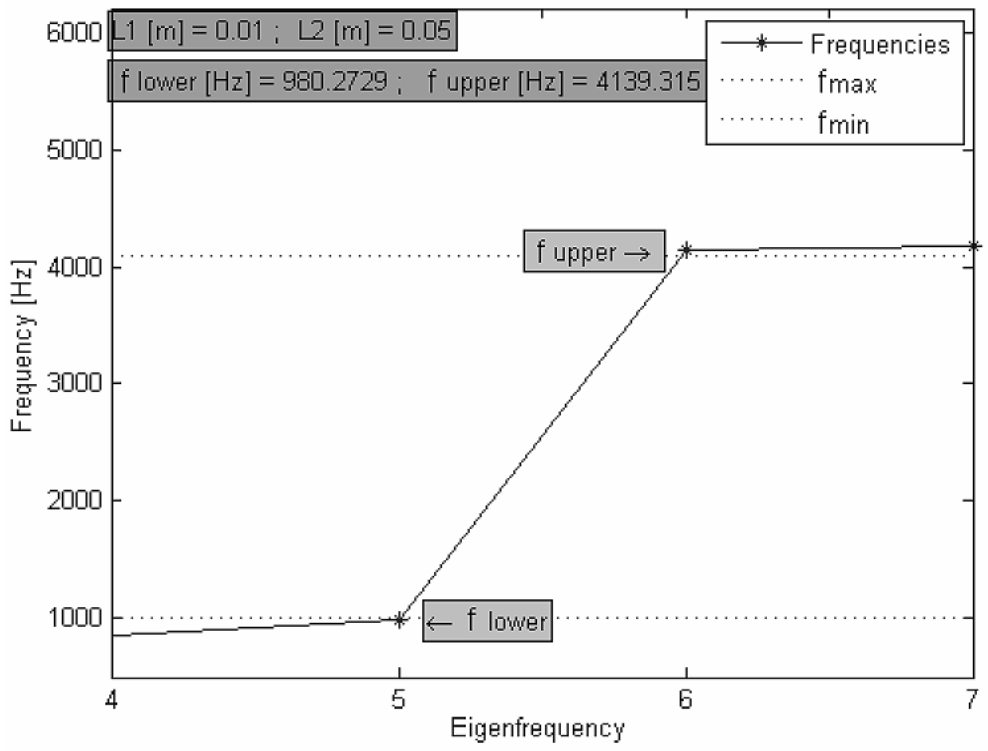

Fig. 10. Resonance gap obtained for example 2.

\subsection{Structural improvement results - Example 2}

The second example considers the experimental specimen illustrated in Fig. 7 b). This specimen is designed to have a resonance gap with a minimum $\left(f_{\text {min. }}\right)$ and maximum $\left(f_{\max }\right.$. bounds of $1000 \mathrm{~Hz}$ and $4100 \mathrm{~Hz}$, respectively. The length of each material should be $0.01 \leqslant \mathrm{~L}_{1} \leqslant 0.05 \mathrm{~m}$ and $0.01 \leqslant \mathrm{~L}_{2} \leqslant 0.05 \mathrm{~m}$. Fig. 10 is obtained by applying the developed design procedure.

Figure 10 illustrates the resonance gap obtained where the dotted lines represent the desired minimum $\left(\mathrm{f}_{\text {min. }}\right)$ and maximum ( $\left.f_{\text {max. }}\right)$ bounds of the resonance gap. The solid line's asterisk represent the obtained design lower $\left(f_{\text {lower }}\right)$ and upper $\left(\mathrm{f}_{\text {upper }}\right)$ bounds of the resonance gap. Table 2 indicates the target and the obtained values.

The lower bound of the resonance gap $\left(f_{\text {lower }}\right)$ is $20 \mathrm{~Hz}$ lower than the minimum required ( $f_{\text {min. }}$ ), see Table 2, leaving room for some optimization of the length of material $1\left(\mathrm{~L}_{1}\right)$ which can be decreased in order to approximate the lower and minimum bounds of the resonance gap. A decrease in $\mathrm{L}_{1}$ may be seen as advantageous since the total size of the structure will decrease, and if the weight of the structure and/or the cost of the material are to be accounted for, these will decrease.

\subsection{Structural improvement results - Example 3 -Decrease in $L_{1}$ min.}

In this third structural improvement example, let us continue to consider that material 1 is steel and material 2 is cork agglomerate and a desired resonance gap with minimum ( $f_{\text {min. }}$ ) and maximum $\left(f_{\max }\right)$ bounds of $1000 \mathrm{~Hz}$ and $4100 \mathrm{~Hz}$, respectively. The length of each material, which differs from example 2 , should be $0.001 \leqslant \mathrm{~L}_{1} \leqslant 0.05 \mathrm{~m}$ and $0.01 \leqslant \mathrm{~L}_{2} \leqslant 0.05 \mathrm{~m}$. By applying the developed design method Fig. $11 \mathrm{a}$ ) and b) are obtained. 
Table 3

Target and design values for example 3

\begin{tabular}{lcc}
\hline & Target & Design (obtained) \\
\hline $\mathbf{f}(\mathbf{H z})$ & $\mathrm{f}_{\min }<1000$ & $\mathrm{f}_{\text {lower }}=987$ \\
$\mathbf{f}(\mathbf{H z})$ & $\mathrm{f}_{\max .}>4100$ & $\mathrm{f}_{\text {upper }}=4139$ \\
$\mathbf{L}_{1}(\mathbf{m})$ & $0.001 \leqslant \mathrm{~L}_{1} \leqslant 0.05$ & 0.0098498 \\
$\mathbf{L}_{2}(\mathbf{m})$ & $0.01 \leqslant \mathrm{~L}_{2} \leqslant 0.05$ & 0.05 \\
$\mathbf{L}_{T}(\mathbf{m})$ & $0.02 \leqslant \mathrm{~L}_{T} \leqslant 0.10$ & $\approx 0.05985$ \\
\hline
\end{tabular}

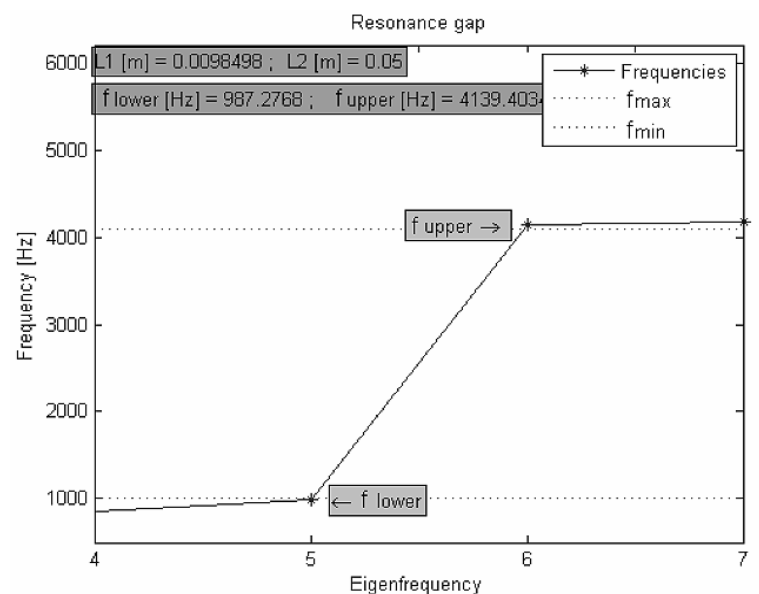

(a)

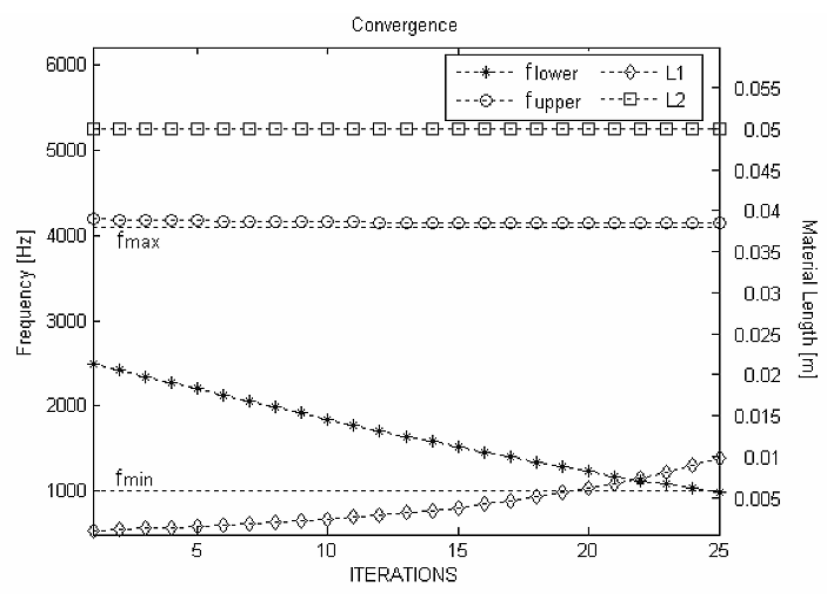

(b)

Fig. 11. Example 3: a) Resonance gap obtained; b) Frequencies and material length convergence.

Figure 11 a) illustrates the resonance gap obtained between the lower $\mathrm{f}_{\text {lower }}$ and upper $\mathrm{f}_{\text {upper }}$ frequencies. Figure 11 b) illustrates the convergence history for the frequencies and material length where the asterisk line represent the obtained design lower ( $\left.f_{\text {lower }}\right)$, the circle line represent the obtained upper $\left(f_{\text {upper }}\right)$ bounds of the resonance gap, the diamond line represent the obtained length for material $1\left(\mathrm{~L}_{1}\right)$ and the square line represent the obtained length for material $2\left(\mathrm{~L}_{2}\right)$. Table 3 indicates the target and the obtained design values.

In this example, the obtained design length of material $1\left(\mathrm{~L}_{1}\right)$ is $0.0098 \mathrm{~m}$, which is less than the value of $0.01 \mathrm{~m}$ obtained in example 2 due to the inputted length of material layer 1 which was of $0.001 \mathrm{~m}$. So being, it is noticed that the input length of material $1\left(\mathrm{~L}_{1}\right)$ should be the minimum length allowed, i.e., $\mathrm{L}_{1}=\mathrm{L}_{1}$ min, in order to obtain a solution that presents a lower length of material 1 which is advantageous, as previously stated in example 2 . For this example, an approximate reduction of $1.6 \mathrm{~kg} / \mathrm{m}^{3}$ is obtained (reduction in terms of mass density).

It is also confirmed that as the length of material $1\left(\mathrm{~L}_{1}\right)$ increases the lower bound frequency of the RG ( $\left.f_{\text {lower }}\right)$ decreases and the upper bound frequency of the RG ( $\left.f_{\text {upper }}\right)$ is not significantly affected, being nearly constant.

\subsection{Structural improvement results - Example 4 - Increase in $f_{\max }$.}

In example 4, let us continue to consider that material 1 is steel and material 2 is cork agglomerate. The desired resonance gap minimum and maximum bounds should be of $\mathrm{f}_{\min }=1000 \mathrm{~Hz}$ and $\mathrm{f}_{\max }=10000 \mathrm{~Hz}$, respectively. The length of each material, are the same as in example 3 and should be $0.001 \leqslant \mathrm{~L}_{1} \leqslant 0.05 \mathrm{~m}$ and $0.01 \leqslant \mathrm{~L}_{2} \leqslant$ $0.05 \mathrm{~m}$. By applying the developed design method Fig. $12 \mathrm{a}$ ) and b) are obtained.

Figure 12 a) illustrates the resonance gap. Figure 12 b) illustrates the frequencies and material length convergence. Table 4 indicates the target and the obtained design values.

The same line of thought may be applied to the length of material layer 2 which should be inputted as the maximum length allowed, i.e., $\mathrm{L}_{2}=\mathrm{L}_{2}$ max, in order to obtain a solution that presents a lower length of material 2 which is advantageous for the same reasons as those presented for material 1 . 
Table 4

Target and design values for example 4

\begin{tabular}{lcc}
\hline & Target & Design (obtained) \\
\hline $\mathbf{f}(\mathbf{H z})$ & $\mathrm{f}_{\min .}<1000$ & $\mathrm{f}_{\text {lower }}=964$ \\
$\mathbf{f}(\mathbf{H z})$ & $\mathrm{f}_{\max .}>10000$ & $\mathrm{f}_{\text {upper }}=10668$ \\
$\mathbf{L}_{1}(\mathbf{m})$ & $0.001 \leqslant \mathrm{~L}_{1} \leqslant 0.05$ & 0.028102 \\
$\mathbf{L}_{2}(\mathbf{m})$ & $0.01 \leqslant \mathrm{~L}_{2} \leqslant 0.05$ & 0.019371 \\
$\mathbf{L}_{T}(\mathbf{m})$ & $0.02 \leqslant \mathrm{~L}_{T} \leqslant 0.10$ & $\approx 0.037$ \\
\hline
\end{tabular}

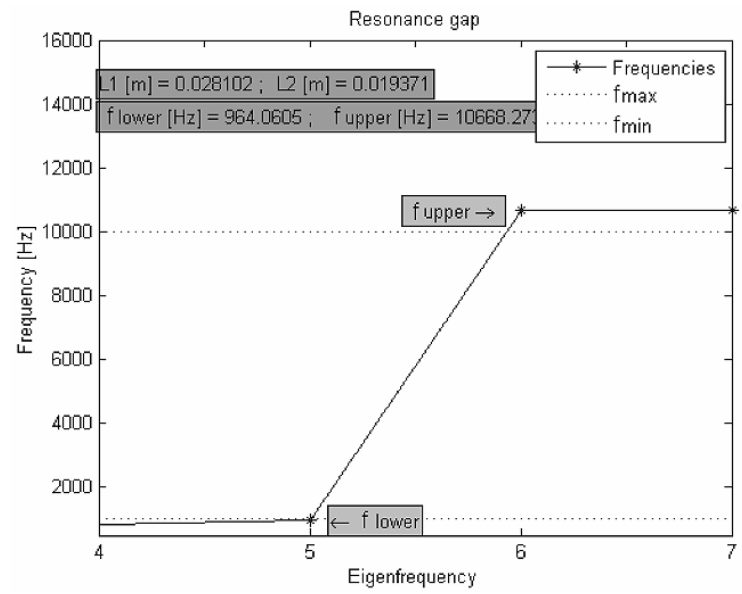

(a)

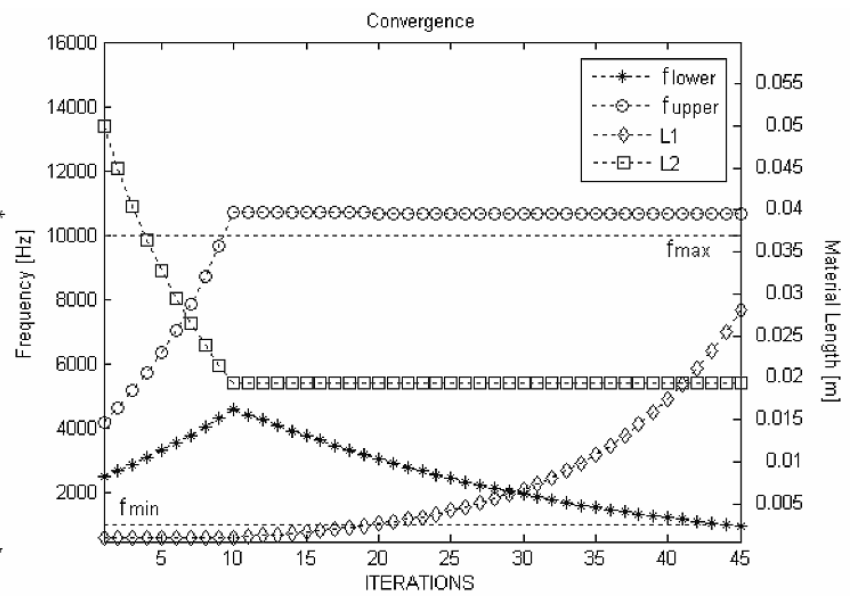

(b)

Fig. 12. Example 4: a) Resonance gap obtained; b) Frequencies and material length convergence.

It is confirmed that as the length of material $2\left(\mathrm{~L}_{2}\right)$ decreases the upper bound frequency of the RG ( $\left.\mathrm{f}_{\text {upper }}\right)$ increases and the lower bound frequency of the $\mathrm{RG}\left(\mathrm{f}_{\text {lower }}\right)$ also increases. It is re-confirmed that as the length of material $1\left(L_{1}\right)$ increases the lower bound frequency of the RG $\left(f_{\text {lower }}\right)$ decreases and the upper bound frequency of the RG ( $\left.f_{\text {upper }}\right)$ is not significantly affected, being nearly constant.

In this example and similar to the previous two, there is room for some optimization of the length of material 1 $\left(\mathrm{L}_{1}\right)$ which can be decreased in order to approximate the lower and minimum bounds of the resonance gap.

The upper bound frequency of the RG $\left(\mathrm{f}_{\text {upper }}\right)$ is slightly higher than the maximum required ( $\mathrm{f}_{\text {max. }}$ ), leaving room for some optimization of the length of material $2\left(\mathrm{~L}_{2}\right)$ which can be increased in order to minimize the difference between the two values. An increase in length of material $2\left(\mathrm{~L}_{2}\right)$ may be seen as disadvantageous since the optimized RG would present a smaller bandwidth then the obtained RG, the total size of the structure will increase, and if the weight of the structure and/or the cost of the material are to be accounted for, these will increase. On the other hand, one may be lead to maximize the RG by maximizing the difference between the upper bound and the maximum required frequency $\left(f_{\max }\right.$.) of the RG. But in contrast to the insignificant effects that an increase in the length of material $1\left(\mathrm{~L}_{1}\right)$ have in the upper bound frequency $\left(\mathrm{f}_{\text {upper }}\right)$, a decrease in the length of material $2\left(\mathrm{~L}_{2}\right)$ leads to an increase of the lower bound frequency of the RG ( $\left.f_{\text {lower }}\right)$. Consequently this would have to lead to an increase of the length of material $1\left(\mathrm{~L}_{1}\right)$ to decrease the lower bound frequency of the $\mathrm{RG}\left(\mathrm{f}_{\text {lower }}\right)$ below the minimum required $\left(f_{\text {max. }}\right)$ and to all the disadvantages previously referred of a longer, heavier and possible more expensive structure.

\subsection{Structural optimization results}

From the previous examples, let us consider examples 3 and 4 for which the structural optimization problem formulated in Section 6.2 is solved. The results obtained are presented in Tables 5 and 6 for the examples 3 and 4 , respectively.

The structural optimization results present a lower frequency bound $\left(\mathrm{f}_{\text {lower }}\right)$ nearby the minimum required frequency $\left(f_{\min }\right.$. due to the decrease of the length of material $1\left(\mathrm{~L}_{1}\right)$, as intended. So being, the disadvantages previously 
Table 5

Target, design and optimized values for example 3

\begin{tabular}{lccc}
\hline & Target & Design procedure & Design (optimization) \\
\hline $\mathbf{f}(\mathbf{H z})$ & $\mathrm{f}_{\min }<1000$ & $\mathrm{f}_{\text {lower }}=987$ & $\mathrm{f}_{\text {lower }}=999.57$ \\
$\mathbf{f}(\mathbf{H z})$ & $\mathrm{f}_{\max .}>4100$ & $\mathrm{f}_{\text {upper }}=4139$ & $\mathrm{f}_{\text {upper }}=4173$ \\
$\mathbf{L}_{1}(\mathbf{m})$ & $0.001 \leqslant \mathrm{~L}_{1} \leqslant 0.05$ & 0.0098498 & 0.0097947 \\
$\mathbf{L}_{2}(\mathbf{m})$ & $0.01 \leqslant \mathrm{~L}_{2} \leqslant 0.05$ & 0.05 & 0.049844 \\
$\mathbf{L}_{T}(\mathbf{m})$ & $0.02 \leqslant \mathrm{~L}_{T} \leqslant 0.10$ & $\approx 0.05985$ & $\approx 0.05963$ \\
\hline
\end{tabular}

Table 6

Target, design and optimized values for example 4

\begin{tabular}{lccc}
\hline & Target & Design procedure & Design (optimization) \\
\hline $\mathbf{f}(\mathbf{H z})$ & $\mathrm{f}_{\min .}<1000$ & $\mathrm{f}_{\text {lower }}=964$ & $\mathrm{f}_{\text {lower }}=998$ \\
$\mathbf{f}(\mathbf{H z})$ & $\mathrm{f}_{\max .}>10000$ & $\mathrm{f}_{\text {upper }}=10668$ & $\mathrm{f}_{\text {upper }}=10185$ \\
$\mathbf{L}_{1}(\mathbf{m})$ & $0.001 \leqslant \mathrm{~L}_{1} \leqslant 0.05$ & 0.028102 & 0.025356 \\
$\mathbf{L}_{2}(\mathbf{m})$ & $0.01 \leqslant \mathrm{~L}_{2} \leqslant 0.05$ & 0.019 & 0.020303 \\
$\mathbf{L}_{T}(\mathbf{m})$ & $0.02 \leqslant \mathrm{~L}_{T} \leqslant 0.10$ & $\approx 0.0471$ & $\approx 0.0457$ \\
\hline
\end{tabular}

referred of a longer, heavier and possible more expensive structure are now minimized in the considered constraints domain.

\section{Conclusions}

A study on the dynamical characterization of passive attenuation of longitudinal vibrations through multi-laminated periodic bars is presented. Analytical, numerical and experimental results are presented to validate the models used. In order to work in a lower frequency range of interest we proposed to use a pair of steel and cork agglomerates due to the high contrast of the wave propagation speed for which a linear analysis showed to be enough to characterize its dynamical behavior in the tested conditions. The main conclusions are:

- It is possible to design, develop and build specimens for frequency ranges with interest for mechanical engineering applications by the proposed methodology. The proposed design procedure obtains, whenever it is possible, the cell parameters necessary to satisfy the values of lower frequency bound ( $f_{\text {lower }}$ ) nearby the minimum required frequency $\left(\mathrm{f}_{\text {min. }}\right.$ )

- An effective structural optimization based on the main concepts developed with the improvement problem can be formulated and implemented to obtain shorter and lighter weight periodic structures.

- A relation to analyze the wave propagation in simple finite structures is achieved through a modal analysis (finite repetitive structure), harmonic analysis (finite medium) or a Bloch wave analysis (infinite repetitive structure) as it is presented (see Fig. 9). No mention to this triple relation was found in the researched literature.

Several assumptions in this work will be subject to future work. One is the introduction of damping in the model together with the effects of the temperature and humidity changes. Another main concern is on the possible variations of stiffness and strength in long-term use or in overloads.

\section{Acknowledgements}

The authors wish to thank Prof. Arlindo Silva (DEM-IST) for kindly supplying the cork agglomerate specimens used in this work along with some useful data.

This study received financial support from FCT (Fundação para a Ciência e Tecnologia, Portuguese Science Foundation) through the project PTDC/EME-PME/71488/2006 (NM) and IDMEC-IST (Portugal).

\section{References}

[1] R.A. Ibrahim, Recent advances in nonlinear passive vibration isolators, J Sound Vib 314 (2008), 371-452.

[2] E.I. Rivin, Vibration Isolation of Precision Equipment, Precision Engineering 17 (1995), 41-56. 
[3] C. Yilmaz and N. Kikuchi, Analysis and design of passive band-stop filter-type vibration isolators for low-frequency applications, $J$ Sound Vib 291 (2006), 1004-1028.

[4] C. Yilmaz and N. Kikuchi, Analysis and design of passive low-pass filter-type vibration isolators considering stiffness and mass limitations, J Sound Vib 293 (2006), 171-195.

[5] L. Brillouin, Wave Propagation in Periodic Structures, Dover Phoenix Editions, 2nd Edition, New York, 1946.

[6] C.H. Hodges and J. Woodhouse, Vibration Isolation from Irregularity in a Nearly Periodic Structure: Theory and Measurements, J Acoust Soc Am 74 (1983), 894-905.

[7] D.J. Mead, Wave Propagation in Continuous Periodic Structures: Research Contributions from Southampton, 1964-1995, J Sound Vib 190 (1996), 495-524.

[8] N.W. Ashcrofat and N.D. Mermin, Solid State Physics, Wiley, New York, 1976.

[9] G. Floquet, Sur les équations différentielles linéaires à coefficients doublement périodiques, Ann Sci Ecole Norm Sup 12 (1883), $47-88$.

[10] A.E. Vakakis and C. Cetinkaya, Dimensional Semi-Infinite, Weakly Coupled Layered Systems, Int J Solid Structures 33(28) (1996), 4195-4213.

[11] O. Sigmund and J.S. Jensen, Systematic design of phononic band-gap materials and structures by topology optimization, Phil Trans $R$ Soc Lond A 361 (2003), 1001-1019.

[12] M.I. Hussein, G.M. Hulbert and R.A. Scott, Dispersive elastodynamics of 1D banded materials and structures: analysis, $J$ Sound Vib 289 (2006), 779-806

[13] M.I. Hussein, G.M. Hulbert and R.A. Scott, Dispersive elastodynamics of 1D banded materials and structures: design, J Sound Vib 307 (2007), 865-893.

[14] A.R. Diaz and A.G. Haddow, Design of band-gap grid structures, Structural and Multidisciplinary Optimization 29 (2005), $418-431$.

[15] M.I. Hussein, G.M. Hulbert, R.A. Scott, K. Hamza and K. Saitou, Multiobjective evolutionary optimization of periodic layered materials for desire wave dispersion characteristics, Structural and Multidisciplinary Optimization 31 (2006), 60-75.

[16] M.A. Fortes, M.E. Rosa and H. Pereira, A cortiça, IST Press, Lisbon, 2004.

[17] J.S. Jensen and N.L. Pederson, On maximal eigenfrequency separation in two-material structures: the 1D and 2D scalar cases, $J$ Sound Vib 269 (2006), 967-986.

[18] S.J. Carson, Model Verification and Validation, Proceedings of the 34th conference on Winter Sessions, 2002.

[19] M.F. Hemez and W.S. Doebling, Model Validation and uncertainty Quantification. 19th International Modal Analysis Conference, Kissimmee, Florida, 2001.

[20] J.F. Mano, The viscoelastic properties of cork, J of Materials Science 37 (2002), 257-263.

[21] H.F.D. Policarpo, A.R. Ribeiro and M.M. Neves, An Experimental Characterization of Cork Storage Modulus for Cork-Steel Applications in Vibration Attenuation, V International Materials Symposium Materiais 2009, April 5 to 8, Lisbon, Portugal, 2009.

[22] D.J. Ferry, Viscoelastic Properties of Polymers, Wiley, (2nd ed.), New York, 1970.

[23] M.A. Kosevich, On a simple model of the photonic or phononic crystal, JEPT Letters 74 (2001), $633-637$.

[24] N. Kikuchi, Finite Element Methods in Mechanics. Cambridge University Press, 1986.

[25] Ansys Inc, ANSYS: Theory Reference Release 11, Edited by Peter Kohnke, ANSYS, Inc., Canonsburg, PA, 2004.

[26] H.F.D. Policarpo, Analytical, Numerical and Experimental Study of the Dynamical Response of Helicoidal Springs and Periodic Bars, MSc Thesis, Instituto Superior Técnico, Universidade Técnica de Lisboa, Portugal, 2008.

[27] M. Leite, J. Lopes and A. Silva, Estudo experimental e analítico, em compressão, de diferentes espumas para aplicação em construção sandwich. $6^{\circ}$ Congresso Nacional de Mecânica Experimental, 27 e 29 de Julho, Açores, Portugal, 2005.

[28] V. Arora, S.P. Singh and T.K. Kundra, Finite element updating with damping identification, J Sound Vib 324 (2009), 1111-1123.

[29] E. Dascotte and J. Strobbe, Updating finite element models using FRF correlation Functions, Dynamic Design Solutions, Belgium, September 1998

[30] M. Meo and G. Zumpano, Damage assessment on plate-like structures using a global-local optimization approach, Optim Eng 9 (2008), 161-177. 

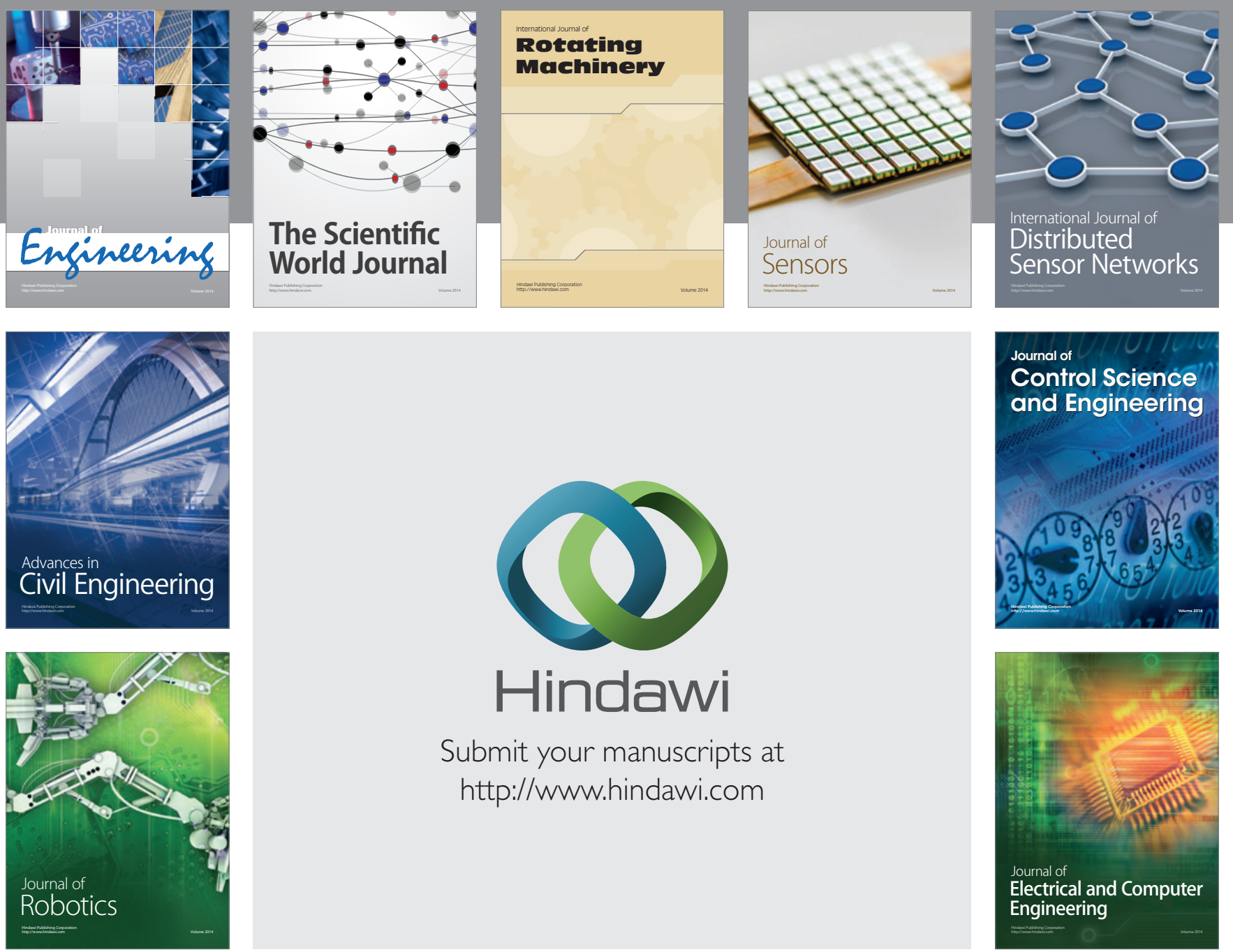

Submit your manuscripts at

http://www.hindawi.com
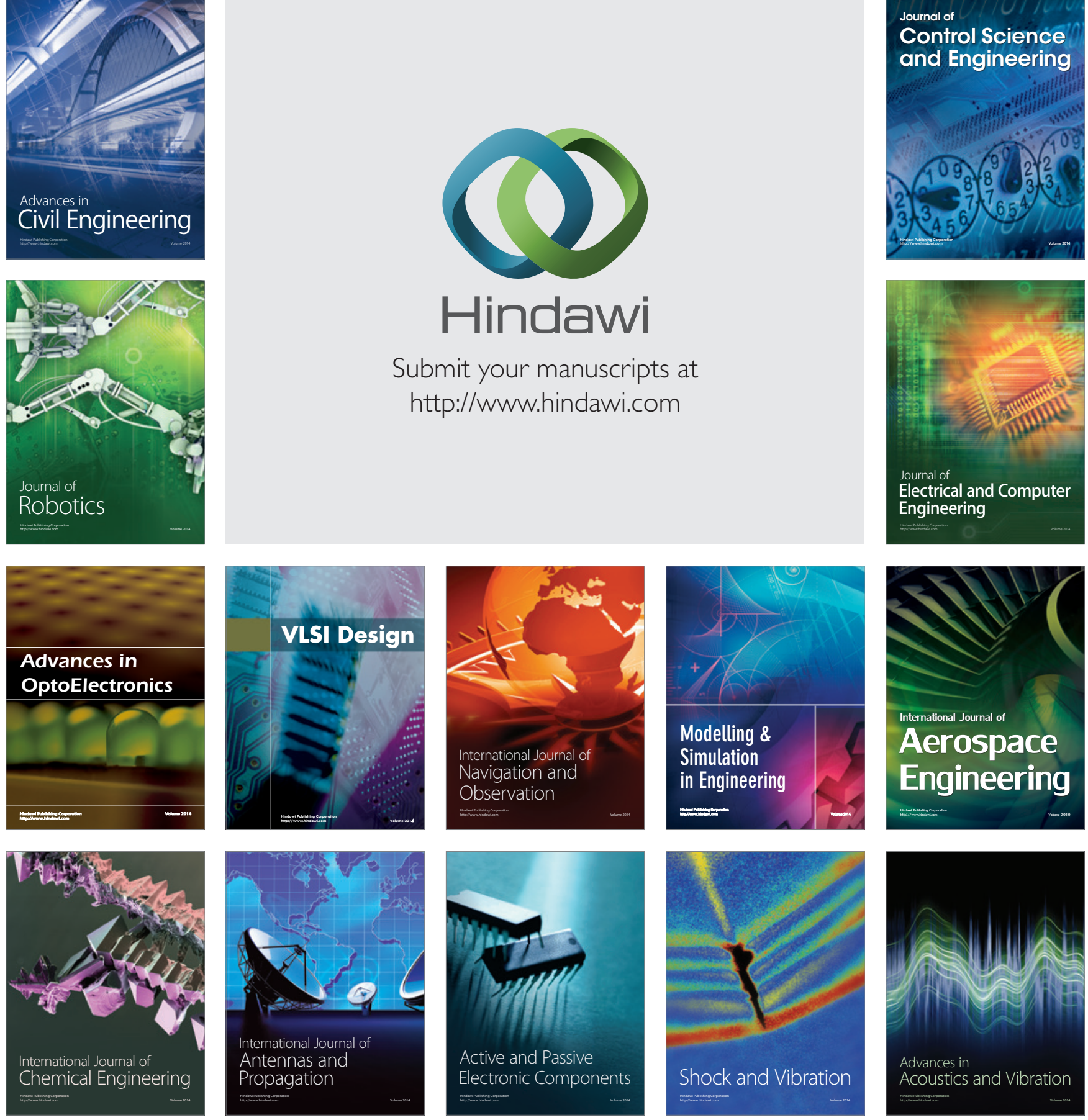